\title{
CLOVIS BEVILAQUA - O COMPARATISTA
}

\author{
Oração de paraninfo na solenidade de colação de gráu da \\ da turma "Clóvis Bevilaqua", de bachareis diplomados \\ pela Faculdade de Direito da Universidade do \\ Paraná, em 8-10-1959.
}

\section{Oscar Martins Gomes}

\author{
Professor catedrático de Direito Internacional \\ Privado
}

\begin{abstract}
Introito
Nesta semana memorável, em tôdas as cidades brasileiras onde exista um templo de direito, de maior ou menor amplitude, celebra-se o ofício de exaltação à personalidade de quem foi em vida um sábio e um santo.

Numa existência de oitenta e cinco anos, dedicada, desde a adolescência, ao estudo, à meditação, à análise, à solução dos problemas do ser e do não ser, e ao exame e orientação das formas estruturais da sociedade e dos casos cotidianamente ocorridos nas relações humanas, o ilustre varão encarna bem um exemplo, dos mais dignificantes, para ser apresentado aos moços em ascenção na escalada vertiginosa da vida.
\end{abstract}

Depois que o Brasil conquistou sua independência e criou os próprios cursos jurídicos ,em 1827, das levas de seus diplomados foi saindo a elite dos homens de estado, dos políticos, dos professôres, dos juristas, dos grandes letrados e até dos poetas.

Como, no simples gráfico representativo duma cordilheira, os pontos mais elevados logo se destacam aos olhos do observador, no primeiro século da emancipação cultural do nosso país três altíssimos cimos impuzeram sua magestade no pensamento jurídico das Américas: Teixeira de Freitas, Ruy Barbosa e Clóvis Bevilaqua.

As oportunidades da passagem do centenário dos dois primeiros deram lugar já ao estudo aprofundado de suas individualidades marcantes, de 
seus méritos e de sua influência na formação política e social brasileira, com a divulgação renovada das obras de cada um.

Agora, a assinalação de igual evento, quando Clóvis, determinou maior e mais apurado exame de tôda a sua produção intelectual, que vai ser reeditada pelo Instituto Nacional do Livro, para distribuição entre bibliotecas públicas, centros de estudo e tribunais de justiça. $\mathrm{E}$ um Congresso Nacional de Direito, em cuja Comissão Executiva tivemos a honra de ver nosso nome incluido, reune-se nêstes dias no Ceará, terra natal do homenageado, com a participação de juristas de todos os Estados, para discussão de seleto temário.

Falando aos moços que ora são investidos nas insígnias do bacharelado em direito, modêlo melhor não poderíamos colocar-lhes à frente do que a figura excelsa de Clóvis, com seus atributos de acurada dedicação ao estudo, de trabalho perseverante, de benemerências públicas, de virtudes privadas, de modéstia e desambição, de bondade e nobreza, de pureza de sentimento e de arraigado senso de humanidade e de civismo.

E como cartilha de conduta aos moços em geral, notadamente aos cultores do direito, devemos proclamar, nesta solenidade antecipada em louvor ao grande Mestre e sob sua égide, a magnitude daquela notável oração que êle denominou "meu credo jurídico e político", como um evangelho de definição e exaltação do direito, da liberdade, da moral, da justiça, da democracia e do patriotismo.

$\mathrm{Na}$ variedade e riqueza da bibliografia de Clóvis, ante a impossibili- dade de lhe abranger e participar todos os setores, passamos a desenvolver alguns tópicos na apreciação de suas atividades como autorizado comparatista do direito.

\section{Clóvis Bevilaqua - o comparatista}

A criação, na Europa, em meados do século XIX, de cátedras de direito comparado, consoante ocorreu, em 1846, na Universidade de Paris, trouxe mais acentuado ânimo às pesquisas jurídicas, sendo certo ainda que a organização, já no século $\mathrm{XX}$, de institutos de direito comparado, como o da Universidade de Munich, em ... 1916, fizeram redobrar o interêsse pelo exame comparativo do direito nas esferas culturais.

Edouard Lambert, uma das vozes mais autorizadas nêsse setor, pois, durante quarenta anos, se dedicou ao estudo e ao ensino do direito comparado na Faculdade de Direito de Lyon, cujo instituto, de análoga finalidade, fundou e dirigiu também $\mathrm{m}$ largo período, considerava o direito comparado um domínio comum às ciências jurídicas, econômica e social, conforme anota o professor Pierre Garraud.

Daí reunir o volumoso "Recueil d'Etudes en l'honneur de Edouard Lambert", publicado em 1938 por aquela Faculdade, eruditos estudos sôbre apreciável variedade de assuntos que escapam ao âmbito do direito privado, onde mais frequentemente se desenvolvem as pesquisas comparatistas.

Os temas sôbre história, religião, economia, sindicalismo, trabalhismo, sociologia e política, ligados sempre 
à evolução do direito, formam o vasto repositório de tão importante coletânea.

Clóvis Bevilaqua, já nos albores de sua atividade intelectual, se sentira atraído para os estudos filosóficos e sociológicos. Sob o lábaro da "escola do Kecife", orientada pela genialidadé de l'ovias Barreto, o jovem pensador passou a participar do grupo luzıdıo dos componentes dêsse notáveil movimento de idéias. Familiariza-se com as criações doutrinárias dos juristas, cientistas e filósofos mais prestigiosos do pensamento europeu, como Ihering, Kant, Stammler, Bluntschli, Comte, Darwin, Cimbali, Haeckel, Savigny, Post e Spencer. Em vigorosa apreciação sôbre o pensamento jurídico e filosófico de Clóvis, mostrando como êle se inclina para o aticismo, oposto ao logicismo Alípio Silveira situa-o nas fileiras do positivismo jurídico sociologista, cujas modalidades se afastam do positivismo filosófico, porque Clóvis - acentua o mesmo jurista pátrio - é evolucionista (monista materialista) e não positivista comteano.

Imbuido dessas idéias novas e contando pouco mais de vinte anos, dá à publicidade "Emilio Littré", "A Filosofia positiva no Brasil", "Estudos de Direito e economia política" e, em 1888, "Conceito antigo e moderno da metafísica", tese de concurso com que ingressou na Faculdade de Direito do Recife, como professor da cadeira de filosofia. Outras obras, mais tarde, na última década do século pasado, ou sejam "A concepção da sociologia em Gumplowicz", "Gustavo Leblon e a psicologia dos povos" e "Juristas filósofos" atestam como a ânsia de saber de Clóvis levava-o a aprofundar-se, cada vez mais, nos soberbos mananciais do pensamento contemporâneo. Aliás, êle sempre encarou o direito como um fenômeno social.

Concluindo seu curso na mencionada Faculdade, em 1882, justamente quando para o corpo docente da mesma entrava, após memorável e ruidoso concurso, Tobias Barreto, só então é que a influência dêsse notável polígrafo se iria fazer sentir no jovem bacharel, que mais tarde haveria de isso confessar, dizendo: "Depois da conclusão do meu curso, foi comparatista, permitindo-lhe maior graças a êle que, por assim dizer, comecei a me interessar por essa bela ciência, ao lado da qual acabava de passar cinco anos sem descobrir-lhe os encantos. Devo a Tobias o inestimável encanto de me ter aberto a inteligência para ver o direito".

De modo que, com o espírito saturado de sólida cultura sociológica e filosófica, quando passou a aprofundar-se na vasta e opulenta seara dos estudos jurídicos, trazia já Clóvis consigo a firme visão adequada que o tornava merecedor do título de jurista filosófo, com que vem consagrando nas homenagens atuais do seu centenário.

Sua cultura assim onímoda alargando-lhe os horizontes intelectuais, facilitava-lhe sobremaneira a pesquisa liberdade nas elucubrações para verificar as causas da diferenciação do direito escrito nos diversos países.

Acresce a circunstância relevante de haver sido Clóvis investido, já na era republicana, na cátedra de legis- 
laçäo comparada da Faculdade do Recife. Publicou então, em 1853, seu livro: "Resumo das lições de legislaçao comparada sôbre o direito privado". Araripe Júnior, seu contemporaneo, mostra que êsse livro "fêz época na vida do jurista cearense porque, se até entao ele mostrara para as questoes tilosóficas e literárias, desae o dia daquela publicação tornou pública a sua capacidade para empreender entre nós obra semelnante à realizada por Hermann Pos na Alemanha"... Deve-se calcular que $\checkmark$ protessor de direito, aplicando os princípios já nossos conhecidos ao estudo da legislação do seu país, em confronto com a estrangeira, não podia senão fazer progredir a jurisprudência nacional; e o fêz, porquanto, até seu advento, os trabalhos congêneres do Brasil se tinham limitado à oposição ou conformidade material dos têxtos. Clóvis foi mais longe nas suas lições. Procurou a lei da adaptação dos institutos alienígenas e o segrêdo da fusão dêsses institutos com os nossos, isto é, com os de origem portuguesa, deformados pelos costumes coloniais, pelos da escravi. dão africana e até indígenas".

Alentado assim, ainda mais, pelo estudo comparativo do direito, vai-se afirmando cada vez mais, em Clóvis, a personalidade do jurista, do jurisconsulto, do jurisperito, do legislador.

Constitui aquela obra o marco inicial duma riquissima e formosa série de livros de direito, mistos de compêndio e de tratado, devidos à fulgurante cerebração de Clóvis e para a elaboração dos quais a investiga- çấo comparatista forneceu subsídios de grande valia.

Publicando em 1895 o "Direito de família", esclarece êle no prólogo da primeira edição: "O elemento histórico e o comparativo transformam, presentemente, o estudo do direito, e o meu pensamento tentou abeberar-se dêles, para seguir a orientação do momento histórico atual".

Debruçado constantemente sôbre as amplas retortas da investigação livresca, sente Clóvis, na sua faina comparatista, necessidade de melhor indagar as causas dos conflitos de leis e estudar os meios de solucioná-los, seja pela unificação do direito material, seja através da fixação de regras comuns de harmonização. Afeiçoa-se então ao direito internacional privado que define como o "conjunto de preceitos regulares das relações de ordem privada da sociedade internacional", sôbre a qual possui uma concepção própria. $\mathrm{E}$, como consequência, publica, em 1906, s€ precioso livro "Direito internacional privado", que dedica aos moços estudiosos do Brasil, conclamando-os a que volvessem suas atenções para êste departamento do direito, no qual domina o universalismo, sobrepujando ao regionalismo.

Colocava-se assim Clóvis, já então, dentro da concepção que viria mais tarde a ser enunciada por H. C. Gutteridge, ao dizer: "Tout comparatiste doit nécessairemente connaitre le droit international privé, sinon il ne pourra jamais se rendre compte dans quelle mesure les differences de droit constituent un obstacle aux rapports internationaux". (Le droit comparé", trad. fr. de R. David, Paris, 1953). 
Clóvis, muitas vêzes, pegava um instituto jurídico e o dessecava, consoante é fácil comprovar, com exemplos. Assim, quanto à teoria do retôrno, também chamada da devolução, Clóvis alinha, dum lado, os escritores que aceitam e aprovam o retôrno, como Bar, Brocher, Weiss, Fiore, Espinola, Valladão e as legislações que o adotam. Do outro lado, coloca os autores de ponto de vista contrário ao retôrno, como Labbé, Pillet, Lainè, Koehler, Despagnet, Villela e outros, e as legislações que o excluem. Depois, para fundamentar seu ponto de vista favorável ao retôrno, contradiz brilhantemente, uma a uma as opiniões doutrinárias que lhe são opostas, inclusive o jocoso argumento que assemalha o instituto à bola de tenis.

O Código Civil brasileiro de 1916, cujo projeto constitui a maior glória de Clóvis, nada continha sôbre o retôrno. Mas a jurisprudência, adotando os ensinamentos dos juristas pátrios, entre os quais Clóvis, admitiu sempre o retôrno, em vários casos debatidos nos tribunais. Posteriormente, a nova Lei de Introdução ao Código Civil, de 1942, enfrentou o problema, e fulminou o retôrno, no art. 16, que adota a teoria da referência à lei material estrangeira, para sua aplicação ao caso em foco, desde logo. Clóvis, em desacôrdo, com essa orientação, the adicionou ligeiro reparo, na quarta edição de sua citada obra, de 1944, dizendo apenas: “ $\mathrm{E}$ amputar a lei estrangeira, que a lei pátria manda aplicar".

Igualmente, no seu erudito estudo sôbre a lei reguladora da capacidade em geral, que deve ser determi- nada pelo estatuto pessoal, examina o velho dissídio entre o domicílio e a nacionalidade. $\mathrm{E}$, reputando as opiniões contrárias, defende denodadamente o princípio da nacionalidade, com fortes argumentos.

A êsse respeito, o Código Civil de 1916 trazia, na sua Lei de Introdução, dispositivos expressos, seguindo o critério da lei nacional, de acôrdo com a tradição brasileira, não obstante a opinião contrária de Teixeira de Freitas, que, acompanhando Savigny, era favorável ao princípio domiciliar, incorporado depois ao Código Civil da Argentina de 1869. Mas, a nova Lei de Introdução, atendendo a razões plausíveis, quebrou aquela continuidade, passando a adotar a lei do domicílio da pessoa.

O velho a acatado Mestre, já nas últimas irradiações do seu esplendente ocaso, limitou-se a anotar, em sen aludido livro, que a inovação vinha. "contra a nossa tradição jurídica e os melhores fundamentos doutrinários".

Imensa e valiosa é a bibliografia de Clóvis Bevilaqua, em prosseguimento, a partir de 1906 até 1944, ano de seu falecimento, através de todos os ramos do direito. 0 âmbito limitado do presente trabalho, visando apenas, nêste passo, à caracterização da individualidade polimorfa do sábio jurista filósofo como comparatista, não comporta maiores desbordamentos.

O método comparatista lhe foi sempre familiar, e isso mostra, mais eloquentemente, seu excelente "Código Civil comentado", vasta obra, ond? menciona em remissão, abaixo de cada artigo, sob o verbete de "legisla- 
ção comparada", os números dos dispositivos correspondentes de outras legislações.

\section{Final}

Os derradeiros anos da fecunda existência do Mestre egrégio encontram-se assinalados, na sua biografia, pelas contínuas manifestações de estima e apreço que lhe eram tributadas.

Em dezembro de 1942, contando já oitenta e três anos, serviu de paraninfo à turma de bachareis da $\mathrm{Fa}$ culdade Nacional de Direito, oportunidade em que, na solenidade da colação de grau, produziu lúcida e fulgurante oração sôbre "consciência jurídica, consciência moral e elemento ético do direito".

Aliás, nessa época, quando a idade, segundo sua expressão, "com argumentos de estarrecer", o aconselhava a cessar de trabalhar, publicou ainda sua magnífica obra "Direito das Coisas".

Os meus paraninfos desta hora encontrarão na vida de Clóvis e na sua produção um manancial perene de altos, oportunos e dignificantes exemplos. O jovem e talentoso orador da turma, seu ardoroso intérprete, bacharelando Aristides Severo Athayde, já fêz sentir que a todos êles inspira o mesmo intuito de aperfeiçoa- mento e ascenção, dentro de sadia orientação democrática e cristã.

E, para dar-lhes conselhos, porque é que haveríamos agora de formulálos, sem talvez originalidade nem autoridade, quando podemos aqui reproduzir, pelo seu acêrto e qualidade, os conselhos que, em 1934, numa visita ao Recife, onde se diplomara, dirigiu aos moços o inolvidável Mestre, cujo nome encima o quadro de formatura de hoje, como seu conspícuo patrono?

Por isso, finalizando, declamamos e proclamamos estas palavras de Clóvis Bevilaqua, para que bem gravadas fiquem na consciência de cada bacharelando: "Sêde, antes de tudo, brasileiros, em segundo lugar americanos, sem desconhecer que sois, sempre e em todos os casos, membros ativos de tôda a família humana. Ser brasileiro é sentir que em nossa alma vibram, com o sentimento da pátria, as aspirações liberais, que são a característica inconfudível de nossa evolução política e intelectual. Ser americano é sentir que, em nosso continente, há um ambiente próprio de paz e harmonia que torna verdadeiramente irmãs as nações, que aqui surgiram para a vida, a atividade industrial e a cultura. Ser membro consciente da família humana é solidarizar-se com a civilização, que vai da verdade, do conforto e dos bens morais". 